\title{
Rancang Bangun Pengaman Sepeda Motor Menggunakan RFID Berbasis Arduino
}

\author{
Yudhi Afriyan, Muhammad Ridha Fauzi* \\ Program Studi Mesin Otomotif, Fakultas Teknik, Universitas Muhammadiyah Riau \\ Jl. Tuanku Tambusai Ujung No. 1 Pekanbaru \\ *E-mail: mridhafauzi@umri.ac.id
}

\begin{abstract}
The safety of a motorcycle is very important for vehicle owners. Until now, most motorbikes still rely only on the key to contact the vehicle itself. In the case of vehicle theft, it is very easy for the perpetrator of the theft to use the letter " $T$ " key. Therefore an additional vehicle safety is required which is difficult to break apart from the ignition key. The purpose of this research is to design and implement motorcycle safety using Arduino-based Radio Frequency Identification (RFID) as additional vehicle safety. The author uses an RFID card / tag to add security to the vehicle starting system with a card / tag reading distance that can be read by an RFID reader. The ID code on the RFID Card must be inputted into the Arduino so that the RFID reader can read the ID Card that has been inputted into the Arduino. Based on the results of the tests that have been done, it is found that the reading distance of the RFID Card / Tag ranges from $1 \mathrm{~cm}$ to $3.5 \mathrm{~cm}$. If the correct ID code is inputted, the electrical system is active and vice versa if the ID code entered is wrong, the buzzer will sound and the electrical system in the vehicle is not active / does not turn

on.
\end{abstract}

Keywords:Motorcycle security, RFID, RFID Card/Tag, Arduino, Buzzer

\begin{abstract}
Abstrak
Keamanan sebuah sepeda motor sangatlah penting bagi pemilik kendaraan. Sampai saat ini kebanyakan sepeda motor masih menggantungkan keamanannya hanya pada kunnci kontak kendaraan itu sendiri. Pada hal pencurian kendaraan sangat mudah dilakukan oleh pelaku pencurian dengan menggunakan kunciletter"'T". Oleh karenaitu dibutuhkan pengaman kendaraan tambahan yang sulit untuk dibobol selain kunci kontak tersebut. Tujuan dari penelitian ini adalah untuk merancang dan mengimplementasikan pengaman sepeda motor menggunakan Radio Frequency Identification (RFID) berbasis Arduino sebagai pengaman tambahan kendaraan. Penulis menggunakan Card/Tag RFID untuk menambah pengaman pada sistem starting kendaraan dengan jarak pembacaan Card/Tag yang dapat dibaca oleh reader RFID. Kode ID pada Card RFID harus diinputkan ke dalam Arduino agar reader RFID dapat membaca ID Card yang telah diinput kedalam Arduino.Berdasarkan hasil pengujian yang telah dilakukan diperoleh bahwa jarak pembacaan Card/Tag RFID berkisar antara $1 \mathrm{~cm}$ sampai 3,5 cm.Jika diinputkan kode ID yang benar maka sistem kelistrikan aktif dan sebaliknya jika kode ID yang diinput salah maka buzzer berbunyi dan sistem kelistrikan pada kendaraan tidak aktif/tidak menyala.
\end{abstract}

Kata kunci:Keamanan sepeda motor, RFID, Card/Tag RFID, Arduino,Buzzer

\section{Pendahuluan}

Perkembangan dunia otomotif sampai saat ini belum diiringi dengan pengamanan kendaraan yang maksimal dari pencurian terutama pada sepeda motor yang harga jualnya relatif murah. Keamanan yang dimaksudkan di sini adalah dari sisi kunci kontak. Sepeda motor dengan kunci kontak standar masih kurang aman kalau hanya memakai kunci kontak pabrikan [1], [2]. Sementara itu sepeda motor yang harganya lebih mahal telah menggunakaan teknologi keamanan kunci kontak yang lebih aman seperti Keyless. Teknologi Keylesssulit untuk dibobol dengan kunci ' $\mathrm{T}$ '. 
Sepeda motor matic, bebek, atau sport sekarang sudah dilengkapi pengaman kunci kontak dengan namaSecure Key Shutter (SKS)[3]. Fitur ini dianggap cukup melindungi motor dari aksi pencurian karena maling susah memasukkan kunci "T" untuk membobol kunci kontak. Namun ternyata tetap saja bisa dijebol bahkan dalam waktu yang singkat. Padahal penutup kunci kontak SKS hanya bisa dibuka menggunakan kunci yang dilengkapi magnet. Tanpa kunci dengan kombinasi magnet yang tepat, SKS tidak dapat dibobol. Tetapi kenyataannya, banyak kejadian motor dicuri dalam waktu singkat meski SKS-nya dalam kondisi tertutup.

Selain itu,saat inibanyak terjadi kehilangan sepeda motor walau sudah menggunakan kunci kontak motor yang mutakhir sekalipun menggunakan kunci magnet model SKS, namun masih bisa dibuka. Biasanya kunci SKS dibuka paksa oleh pencuri, atau menggunakan master kunci sesuai merk motor yang sudah ada magnetnya [4].Spesialis duplikat kunci bisa membuatkan kunci duplikatnya berikut magnet pembuka SKS-nya. Jadi SKS tidak menjamin motor aman dari pencurian. Sebaiknya digunakan juga pengaman tambahan.

Beberapa penelitian telah dilakukan untuk memperkuat keamanan sepeda motor seperti [5] membuat aplikasi kendali sepeda motor berbasis bluetooth menggunakan android. Sistem ini digunakan untuk menyalakan mesin dan alarm sepeda motor dari jarak tertentu. Kontrol utama dari sistem ini adalah Arduino UNO dan android sebagai remote. Android mengirimkan perintah ke HC-05 Bluetooth shield, kemudian diteruskan ke Arduino. Sistem ini digunakan untuk menemukan sepeda motor dengan cara menyalakan alarm.

Selain itu pengaman terhadap kunci sepeda motor dapat juga dilakukan dengan menggunakan Radio Frequency Identification (RFID). Pada penelitian ini media input adalah kartu tag ID dan RFID yang berfungsi sebagai pengaman kendaraan bermotor. Kartu tag ID berisikan kode-kode spesifik atau unikyang digunakan sebagai kunci untuk menghidupkan atau memutuskan kabel saklar dan busi serta alarm yang terpasang. Namun system yang dibuat ini masih ada kelemahannya [6].

Berdasarkan beberapa informasi dan penelitian di atas maka telah dirancang pengaman sepeda motor menggunakan RFID berbasisArduino.Adapun tujuan perancangan ini adalah untuk mengimplementasikan pengaman sepeda motor menggunakan RFIDberbasisArduino sebagai pengaman ganda kendaraan untuk mengatasi peningkatan pencurian sepeda motor.Pengaman sepeda motor ini telah diprogram dengan pengaman starter kendaraan memakai Card/Tag yang telah terpasang di kendaraan tanpa takut kendaraan dapat dibobol dan di-startermelalui kunci kontak. Sepeda motor tidak dapat dihidupkan kecuali dengan menginput/mentappingCard/Tagyang benar yang sudah diprogram melalui Arduino. Pengaman sepeda motor ini dilengkapi denganbuzzer sebagai pengganti alarm jika ada kejadian tidak valid-nya Card/Tag yang diinput.

\section{Methodologi}

Pengaman sepeda motor menggunakan RFIDberbasis sistem kendali mikrokontroler Arduino UNO berfungsi sebagai pengaman ganda sepeda motor dari aksi pencurian.Rancangan sistem pengaman ini terdiri dari dua tahap yaitu perancangan sistem perangkat keras dan perancangan sistem perangkat lunak.

Diagramblok perancangan pengaman sepeda motor dapat dilihat pada Gambar 1 di bawah ini.

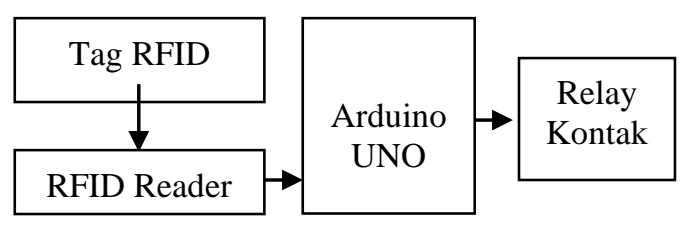

Gambar 1. Diagram blok perancangan sistem

\subsection{Perancangan Perangkat Keras (Hardware) \\ a. Project Board}

Perancangan mekanik ini bisa juga disebut sebagai pembuatan maket untuk penyimpan serta pelindung alat yang berisi komponenkomponen seperti Arduino UNO, DC Concerter, Relaydan RFID. Pembuatan maket ini sederhana hanya berbentuk persegi panjang yang dibuat sekecil mungkin karena maket ini akan diletakan di dalam sepeda motor.

\section{b. Perancangan Rangkaian Relay dengan Arduino UNO \\ Relay kontak berfungsi sebagai} pemutus/penyambung arus pada kontak yang dikontrol menggunakan RFID. Relay ini saat dalam posisi standby keadaannya adalah No Connected/tidak terhubung pada kontak seperti pada Gambar 2. 


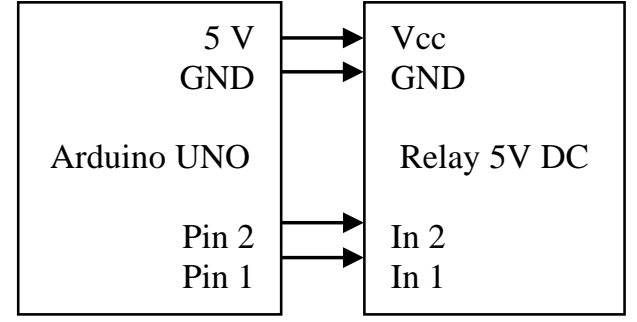

Gambar 2. Konfigurasi Arduino UNO dengan Relay.

\section{c. Perancangan Rangkaian Arduino UNO dengan RFID}

Berfungsi sebagai pengaman yang bekerja menempelkan TagReader RFID. Apabila sesuai maka RFID mengirim data ke mikrokontroler lalu data diolah untuk mengaktifkan kontakrelay. RFID ini bekerja dengan catudaya yang stabil sebesar +5Volt. Pada saat RFID TagCard mendekati RFID Reader pada jarak $\pm 5 \mathrm{~cm}$, RFID Tag Card akan tercatu daya oleh RFID Reader, lalu RFID Tag Card akan mengeluarkan gelombang RF yang berisikan data analogyangselanjutnya akan ditangkap oleh RFID Reader, seperti pada Gambar 3.

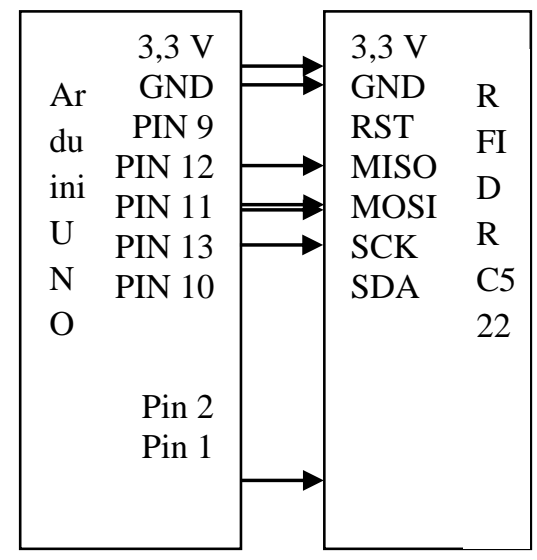

Gambar 3.Konfigurasi Arduino UNO dengan RFID

\section{d. Perancangan Rangkaian DC Converter dengan Arduino UNO}

Catu daya yang digunakan adalah catu daya variable sehinggategangan outputnyadapat ditentukan. Alasan memakai catu daya ini karenaArduino membutuhkan supply tegangan kurang lebih 7 Volt sedangkan dariAccu adalah 12 Volt. Konfigurasinya ditampilkan pada Gambar 4.

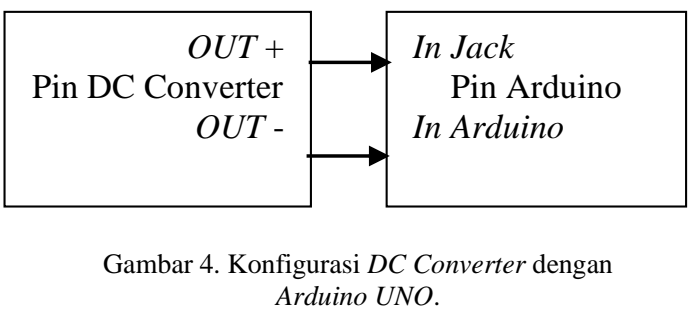

2.2 Perancangan Perangkat Lunak (Software)

Prosedur perancangan perangkat lunak adalah sebagai berikut :

1. Membuat program menggunakan pemrograman Arduio.

2. Mengkompilasi program yang telah dibuat sampai tidak terjadi kesalahan.

3. Pengisian Program.

Perangkat lunak digunakan sebagai sarana untuk membuat program atau bagaimana cara kerja yang kita inginkan dan dihubungkan ke sistem minimummikrokontroler.

Mikrokontroler harus diprogram supaya bisa menjalankan atau mengaktifkan komponenkomponen yang digunakan sesuai dengan yang diinginkan. Penulis menggunakan software Arduino, karena sistem minimum yang digunakan berupa modul mikrokontroler Arduino UNOyang telah dikemas khusus dan diproduksi oleh Arduino.

\subsection{Perancangan dan Pemasangan Alat pada Kendaraan}

Proses perancangan dan pemasangan alat pada kendaraan adalah :

1. Pemasangan box sebagai wadah alat di kap depan kendaraan.

2. Pemasangan relay dengan kunci kontak.

3. Pemasangan switch/tombol rahasia sebagai ON/OFF reader RFID.

4. Pemasangan sumber catu daya Arduino dengan DC Converter yang bersumber dari baterai/accu kendaraan.

5. Pemasangan buzzer dan menghubungkan relay dengan klakson kendaraan.

\subsection{Deskripsi Kerja Sistem}

1. Sistem pengaman kendaraan ini tetapmenggunakan kunci kontak sebagai pengamanutama.

2. Arduino UNOmengontrol RFID dan buzzer ketika Card/Tag ditempelkan dengan Reader RFID, buzzerakan berbunyi ketika data yang diinput tidak valid.

3. RFID sebagai media keamanan ganda kunci kontak pada kendaraan.

4. DC Convertermengontrol besar/kecil nya arus yang masuk kedalam Arduino yang bersumber dari baterai/accu kendaraan. 
5. Relaysebagai saklar digital pada RFID dan buzzer.

6. Reader RFIDdisini berfungsi sebagai kunci ganda, apabila kunci kontak sudah dijebol dan Card/tagRFID tidak terdaftar/belum ditempelkan maka kendaraan tidak akan bisa menyala dan buzzer akan diaktifkan oleh Arduino sehingga menimbulkan bunyi dari klakson kendaraan.

7. Ketika Card/Tag ditempelkan pada reader RFID dengan data yang sesuai, starter kendaraan dapat digunakan dengan menempelkan Card/Tag. Relay disini menyambungkan pengapian kendaraan (dengan keadaan normal). RFID berfungsi untuk menggerakkan relay yang memutus dan menyambungkan sistem pengapian motor.

8. Ketika tag dan reader RFID tidak cocok, maka relay kontak tidak bekerja dan sistem pengapian masihterputus.

\section{Hasil dan Pembahasan}

\subsection{Hasil Perancangan}

Rangkaian sistem keamanan RFID lengkap hasil perancangan dapat dilihat pada Gambar 5. Rangkaian kelistrikan kabel positif kunci kontak sepeda motor terhubung langsung dengan baterai/accu dan coil diputus dan disambung dengan kabel tambahan yang kemudian dihubungkan dengan relay. Arduino mengontrol relay yang inputnya berasal dari RFID.

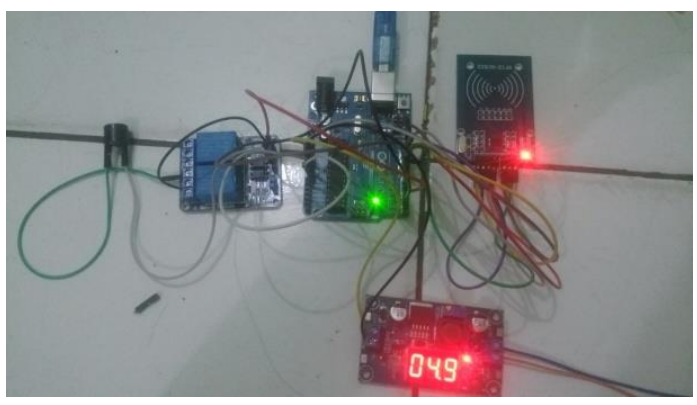

Gambar 5. Sistem Keamanan RFID

Rangkaian komponen-komponen pada Gambar 5diatas terdiri dari beberapa bagian yaitu Input, Proses, Output. Rangkaian Output berupa relay yang berfungsi sebagai saklar digital yang mengubah sinyal analog menjadi sinyal digital. Rangkaian proses berupa Arduinoyang berfungsi sebagai perintah/pengontrol komponen lainnya. DC Converter berfungsi sebagai pengontrol besar kecil arus yang diterima dari baterai dan disalurkan ke Arduino UNO. Buzzer berfungsi sebagai notifikasi berupa bunyi ketika Card/Tag ID yang ditempel ke reader RFID tidak sesuai/tidak valid. Rangkaian Input berupaRFIDyang berfungsi untuk meneruskan perintah penyalaan sistem starter kendaraan oleh Arduino, untuk mengubah data digital yang diterima oleh reader RFID yang berupa Identification (ID) menjadi sebuah sinyal analog.

\subsection{Pengujian RFID}

Pengujian RFID dapat dilakukan menggunakan aplikasi Arduino Idedengan menginputkan codingan program RFID ke dalam Arduino.

Setelah codingan program selesai dimasukkan maka tekan Complete, kemudian Done, maka program yang sudah dicoding benar. Kemudian pilih Upload, Jika sudah muncul Done Uploading, program codingan telah terinput ke dalam Arduino. Setelah itu buka Serrial Monitor dan dekatkan Card/Tag RFID dengan reader RFID nya. Maka akan muncul data dari Card/Tag RFID.

Program RFID dapat dilihat pada gambar 6 di bawah ini.

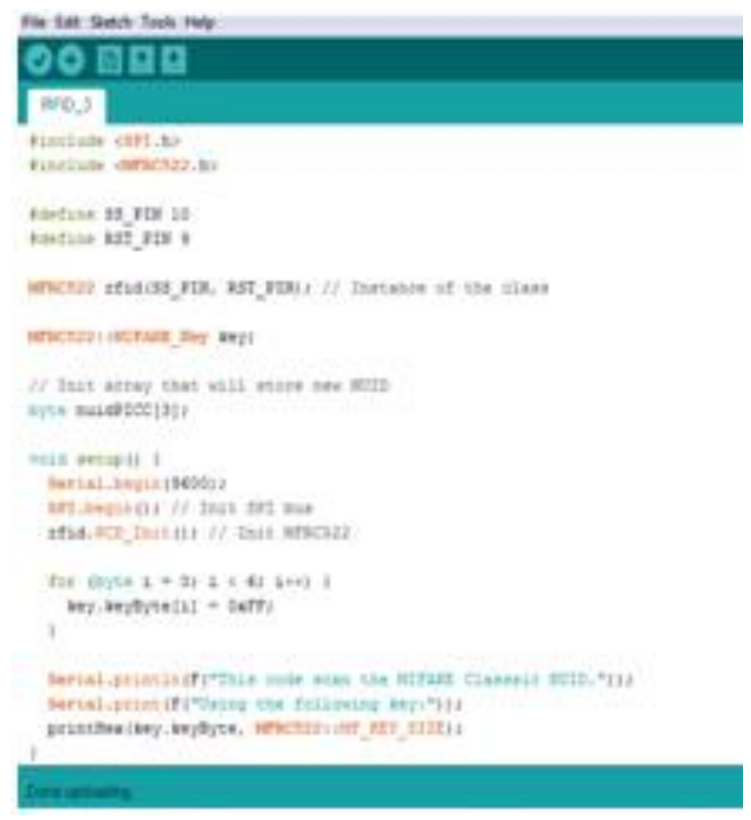

Gambar 6.Program RFID

\subsection{Pengujian Jarak RFID dengan Reader RFID}

Pada pengujian jarak, posisi reader RFID sejajar dengan Card/Tag RFID. Data pada Card/Tag RFID tidak dapat dibaca oleh reader RFID jika posisi keduanya tidak saling tegak lurus. Pengujian RFID ini dilakukan untuk mengetahui jarak baca reader RFID dengan Card/Tag RFID apakah valid/tidak valid. Pendeteksian Card/Tag RFID oleh reader RFID ditandai dengan menyalanya sistem starter 
kendaraan. Hasil pengujian jarak RFID dengan Reader RFID ditampilkan dalam Tabel 1.

Tabel 1. Pengujian jarak baca Reader RFID dengan Card/Tag

\begin{tabular}{ccc}
\hline No & Jarak $(\mathbf{C m})$ & Kondisi Card/Tag RFID \\
\hline 1 & 1 & Valid \\
2 & 2 & Valid \\
3 & 3 & Valid \\
4 & 3,5 & Valid \\
5 & 4 & Tidak Valid \\
6 & 5 & Tidak Valid \\
7 & 6 & Tidak Valid \\
\hline
\end{tabular}

Dari hasil pengujian tersebut dapat dilihat bahwa semakin jauh jarak pembacaan reader RFID antara Card/Tag RFID, maka pembacaan data Identification (ID) pada Card/Tag RFID tidak akan terbaca oleh reader RFIDdan engine sepeda motorpun tidak dapat dihidupkan.

\subsection{Pengujian Identification (ID) pada Card/Tag \\ RFID menggunakan Serial Monitor}

Pengujian ini dilakukan untuk mengetahui program pada Arduino dengan alat, apakah berjalan sesuai dengan harapan atau tidak melalui serial monitor.

\section{COM26 (Arduino/Genuino Uno)}

I

This code scan the MIFARE Classsic NUID. Using the following key: FF FF FF FF FF FF

A new card has been detected.

The NUID tag is:

In hex: A7 C5 D7 93

In dec: $167 \quad 197 \quad 215 \quad 147$

Gambar 7. Data ID pada Card

\section{COM26 (Arduino/Genuino Uno)}

This code scan the MIFARE Classsic NUID

Using the following key: FF FF FF FF FF

A new card has been detected.

The NUID tag is:

In hex: $7 \mathrm{~A}$ A2 $\mathrm{CE} 80$

In dec: 122162206128

Gambar 8. Data ID pada Tag

Gambar 7 menggunakan Card,menunjukkan data yang diinput kedalam program berhasil dibaca oleh reader RFID. Gambar 8menggunakan Tag menunjukkan data yang diinput ke dalam program tidak berhasil dibaca oleh reader RFID/Tidak Valid.

3.5 Pengujian Hasil Card dan Tag RFID

Pada pengujian hasil Card dan Tag, reader RFID hanya dapat membaca Card yang diprogram dalam Arduino dan tidak akan berhasil membaca data Identification (ID) yang berada pada Tag yang telah disediakan. Pengujian ini dilakukan untuk mengetahui apakah Card dan Tag RFID dapat berhasil menghidupkan Relay.Hasil pengujian ditampilkan pada Tabel 2.

Tabel 2. Pengujian data ID pada Card dan Tag RFID

\begin{tabular}{ccc}
\hline No & $\begin{array}{c}\text { Data ID pada Card } \\
\text { dan Tag }\end{array}$ & $\begin{array}{c}\text { Relay } \\
\text { (ON/OFF) }\end{array}$ \\
\hline 1 & 167197215147 & ON \\
2 & 122162206128 & OFF \\
\hline
\end{tabular}

Pada program Arduino, reader RFID hanya dapat diinput satu Identification (ID) pada Card RFID yang bertujuan agar tidak ada orang yang menduplikasi Card RFID dengan kode Identification (ID) yang sama.Identification (ID) ini-pun banyak varian nomor data-nya yang tertanam pada Card/Tag dengan nomor yang random. Pada saat Card nomor 1 ditempelkan pada reader RFID maka relay pada posisi ON dan kendaraan dapat distarter. Ketika Card nomor 2 ditempelkan pada reader RFID maka relay pada posisi OFF dan kendaraan tidak dapat distarter.Jika ingin menambahkan cadangan Card/Tag RFID, cukup memasukan kode Identification (ID) sesuai dengan yang diinput kedalam program Arduino, sedangkan relay mati/OFF jika Identification (ID) pada Card/Tag RFID yang dimasukkan salah karena kode Identification (ID) ini sebelumnya tidak diinput kedalam program codingan Arduino.

\subsection{Pengujian DC Converter}

Hasil pengujian DC Converterdapat dilihat pada Tabel 3.

Tabel 3. Pengukuran tegangan DC Converter

\begin{tabular}{cc}
$\begin{array}{c}\text { Input } \\
(\text { Vdc })\end{array}$ & $\begin{array}{c}\text { Output } \\
\text { (Vdc) }\end{array}$ \\
\hline 12 & 6,7
\end{tabular}

Pada hasil pengujian baterai sebagai sumber arus dengan tegangan $12 \mathrm{Vdc}$ distabilkan oleh DC Converter sehingga arus yang masuk kedalam Arduino sebesar 6,7 Vdc dan Arduinopun menerima tegangan yang cukup dan tidak berlebih. 
3.7 Pengujian Tegangan Input Relay

Hasil pengujian tegangan input Relay ditampilkan pada Tabel 4.

Tabel 4. Pengukuran tegangan input Relay

\begin{tabular}{lc}
\hline \multicolumn{1}{c}{ Titik Pengujian } & Tegangan Input (V) \\
\hline Relay 1 (Kunci Kontak) & 5 \\
Relay 2 (Buzzer) & 5 \\
\hline
\end{tabular}

Input relay memerlukan tegangan sebesar 5 Volt untuk mengaktifkan koil dan keluaran pada Arduino sebesar 4,8 Volt sebagai trigger untuk saklar otomatis.

\subsection{Pengujian Relay}

Dari hasil pengujian pada Tabel 5 dapat dilihat bahwa jika kondisi Logic Relay 1 bernilai $1 \& 0$ maka arus mengalir kerelay danditeruskan ke kunci kontak sehingga jika switch motor starter di-ON kan, maka engine kendaraan dapat dihidupkan. Namun jika Logic Relay bernilai 0 \& 1 maka arus tidak mengalir ke relay sehingga arus juga tidak mengalir ke kunci kontak dan buzzer pun berbunyi sebagai notifikasi tidak valid-nya data ID yang telah diinput.

\subsection{Pengujian Keseluruhan Sistem}

DC Converter memberikan tegangan yang sudah distabilkan dari baterai sebesar 12 Volt menjadi 5 Volt untuk tegangan yang diperlukan oleh Arduino UNO. Dengan adanya tegangan yang diterima dari baterai tersebut, Arduino dapat difungsikan sebagai pengontrol reader $R F I D$, relay dan buzzer. Ketika card yang telah diinputkan ID-nya kedalam Arduino kemudian ditempelkan dengan reader RFID, maka sistem starter kendaraan dapat digunakan dan kendaraanpun dapat dinyalakan. Ketika card yang tidak ada data ID-nya di dalam Arduino dan ditempelkan kereader RFID, maka sistem starter kendaraan tidak dapat digunakan dan Arduino memerintahkan relay untuk membunyikan buzzer sebagai notifikasi tidak valid-nya data ID Card yang telah ditempelkan dengan reader RFID.
Tabel 5. Hasil pengujian Relay

\begin{tabular}{ccl}
\hline & \multicolumn{2}{c}{ LOGIC } \\
\hline $\begin{array}{c}\text { Relay 1 } \\
\text { Kunci } \\
\text { Kontak) }\end{array}$ & $\begin{array}{c}\text { Relay 2 } \\
\text { (Buzzer) }\end{array}$ & \multicolumn{1}{c}{ Keterangan } \\
\hline & & $\begin{array}{l}\text { Ketika LogicRelay1 bernilai } \\
\text { 1\&LogicRelay 2 bernilai 0 maka } \\
\text { starter kendaraan bisa } \\
\text { diaktifkan dan Buzzer tidak } \\
\text { berbunyi. }\end{array}$ \\
\hline & 0 & $\begin{array}{l}\text { Ketika Logic Relay1 bernilai 0 } \\
\text { \&LogicRelay2 bernilai 1 maka } \\
\text { Starter kendaraan tidak akan } \\
\text { bisa diaktifkan dan Buzzer akan } \\
\text { berbunyi sebagai notifikasi tidak } \\
\text { validnya data ID yang di- } \\
\text { inputkan }\end{array}$ \\
\hline
\end{tabular}

Kondisi disaat valid dan tidak validnya keadaan sistem, maka dapat digambarkan dari diagram Gambar 8di bawah ini.

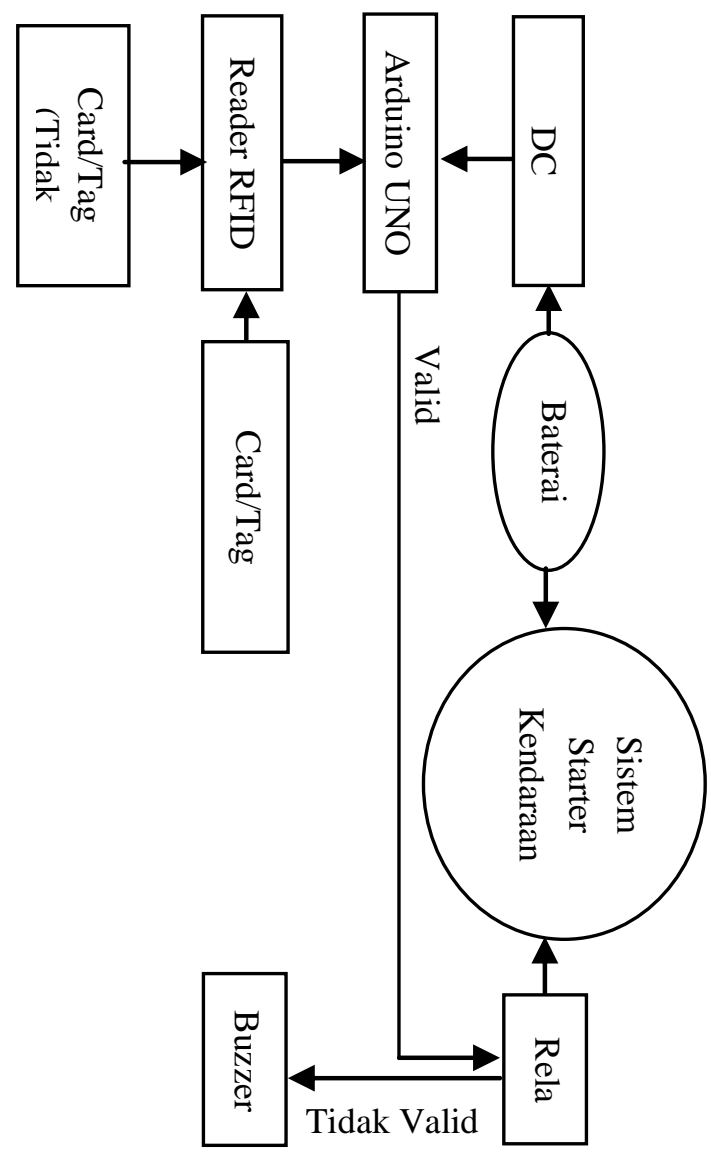

Gambar 8. Kondisi saat valid dan tidak valid 


\section{Simpulan}

Penelitian pengaman sepeda motor menggunakanRadio Frequency Identification (RFID)berbasis Arduinotelah berhasil dilakukan. Setelah dilaksanakan pengujian, maka jarak pembacaan Card/Tag oleh reader RFID berkisar antara 1 sampai dengan $3,5 \mathrm{~cm}$. Kode ID pada Card RFID harus diinputkan ke dalam Arduino agar reader RFID dapat membaca ID Card yang telah diinput tersebut. Jika kode ID pada Card RFID tidak sesuai dengan ID yang diinput kedalam Arduino maka sistem starter kendaraan tidak dapat dihidupkan danbuzzer akan berbunyi. 


\section{Daftar Pustaka}

[1] Davig Yugiansyah, et. al, 2019. Perancangan Pengaman Aktivasi Sepeda Motor Berbasis Arduino Mega 2560, Prosiding Seminar Nasional Teknik Elektro, UNJ, Vol. 4 , Hal. 54-59.

[2] Deri Andesta , Rian Ferdian, 2018. Sistem Keamanan Sepeda Motor Berbasis Mikrokontroler dan Modul GSM. JITCE Vol. 02 No. 02, Hal. 51-63.

[3] TRIBUNPEKANBARU.COM, RENGAT, 2019. Aparat Kepolisian Polres Inhu mengamankan lima orang pelaku pencurian kendaraan bermotor (curanmor)

di

Kabupaten Inhu.

[4] Motorplus.Com, 2019. Maling Gak Sampe Semenit Ngebuka Kontak Motor Yang Sudah Canggih, Ini Buktinya.

[5] Mahfud Ichsan Adi P, 2017. Rancangan Sistem Start Engine Dan Alarm Pada Sepeda Motor Menggunakan Arduino UNO Berbasis Android, Surakarta..

[6] Budy, 2011. Sistem Pengamanan Kunci Sepeda Motor Menggunakan Radio Frequency Identification (RFID), Yogyakarta. 